\title{
Determination of Mirabegron in rat plasma by UPLC-MS/MS after oral and intravenous administration
}

Mirabegron is a kind of $\beta 3$ adrenergic receptor agonist which is an effective drug for the treatment of overactive bladder. In this research, a UPLC-MS/MS method is developed and validated for the study of mirabegron pharmacokinetic in rats. A protein precipitation method is applied for sample preparation with acetonitrile. $\mathrm{m} / \mathrm{z} 397.3 \rightarrow 379.6, \mathrm{~m} / \mathrm{z} 326.4 \rightarrow 121.0$ for mirabegron, tolterodine (IS), respectively in the positive ion mode was performed for quantitation. The method is reliable and reproducible in our study (intra-day precision $\leq 11.06 \%$, inter-day precision $\leq 11.43 \%$ ) with concentration curves linear from 5 to $2500 \mathrm{ng} / \mathrm{mL}(R 2>0.999)$. Stability studies demonstrated that mirabegron was stable under a variety of storage conditions. This method was successfully applied for determining mirabegron in rats after oral and intravenous administration.

KEYWORDS: Urinary bladder, overactive. Adrenergic beta-3 receptor agonists. Plasma. Administration, intravenous. Administration, oral. Rats.

\section{INTRODUCTION}

Overactive bladder $(\mathrm{OAB})$ is a kind of syndrome characterized by symptoms of urinary urgency, frequency, nocturia and urge incontinence ${ }^{1-3}$. It is estimated that in 2018 there were 546 million people suffering from $\mathrm{OAB}$ worldwide. Irwin et al. ${ }^{4}$ revealed that the prevalence of $\mathrm{OAB}$ worldwide is estimated as being greater in women than in men in 2008 (11.6\% vs. 9.7\%, respectively), 2013 (11.7\% vs. 9.8\%) and 2018 (11.9\% vs. 10.0\%) (Irwin and others 2011).

Mirabegron, namely (2-(2-amino-1,3-thiazol-4yl)-N-[4-(2-\{[(2R)-2-hydroxy-2-phenylethyl]amino $\}$ ethyl)phenyl]acetamide), trade name Myrbetriq meer-bet-trick in the US and Betmiga in Europe, is a novel, effective and highly selective $\beta 3$ receptor agonists for the treatment of $\mathrm{OAB}^{5,6}$. It was approved in the United States in July $2012^{7}$. Astellas Pharma Inc. found it is an agonist of the human $\beta 3$-adrenoceptor ${ }^{1}$. The activation of the $\beta 3$ adrenergic receptor in the detrusor can relax the muscle in the bladder and increase bladder capacity. Takusagawa et al. ${ }^{8}$ suggested that CYP3A4 and CYP2D6 are involved in the oxidative metabolism of mirabegron in vitro, although Sawamoto et al. ${ }^{9}$ indicated that these isozymes play a limited role in vivo. Before further pharmacological and pharmacokinetic research is fully possible, it is necessary to first develop an an- 
alytical method for the effective determination of Mirabegron in biological fluids.

A literature survey reveals that several pieces of literature reported the analytical methods for the determination of this $\beta 3$ adrenoceptor agonist mirabegron in biological fluids have been established. Raymond van Teijlingen et al. ${ }^{10}$ developed and validated a liquid chromatography-tandem mass spectrometry (LC-MS/MS) method for determining mirabegron and its metabolites. Zhou et al. ${ }^{11}$ was the only group using Liquid Chromatographic (LC) to Separate Mirabegron Enantiomers on a Chiralpak AY-H Column. However, no piece of literature focused on the ultra performance liquid chromatography-tandem mass spectrometry (UPLC-MS/MS) method for determining mirabegron in biological fluids. Compared with LC and LC-MS/MS, UPLCMS/MS shows a dramatic enhancement in speed, sensitivity, selectivity, robustness, resolution as well as sample throughput.

In the present study, the development of a sensitive and rapid method for estimating mirabegron in plasma was achieved and successfully applied to the pharmacokinetic study of mirabegron after oral and intravenous administration. Acetonitrile precipitation was applied in our work. Separation and quantitation of mirabegron in plasma samples were performed with UPLC-MS/MS. The column was packed with C18 particles of $1.7 \mu \mathrm{m}$, which contribute to higher column performance, efficient separation and short analysis time. The total run time for each sample was shorter than $3 \mathrm{~min}$ (2.5min). Our method behaved faster and more sensitively compared with that of previous studies ${ }^{10,11}$.

\section{EXPERIMENTAL PROCEDURE}

\section{Chemicals}

Mirabegron (Cat: BD 256310, Purity $>99 \%$ ) was obtained from Toronto Research Chemicals, Inc. (Toronto, Ontario, Canada). Tolterodine (internal standard, IS) (Cat: CLS-BD17869, Purity>95\%) was purchased from J\&K Scientific Ltd. (Beijing, China). Acetonitrile was obtained in HPLC grade from Merck KGaA (Darmstadt, Germany), as well as methanol. Formic acid, obtained from Tedia Company (Cincinnati, OH, USA) was HPLC-grade. Millipore Milli-Q purification system (Bedford, MA, USA) was used to prepare ultra-pure water. All other reagents used in the whole experiment were of analytical or HPLC grade.
Ultra performance liquid chromatography and tandem mass spectrometry conditions

UPLC-MS/MS with ACQUITY UPLC H-Class and XEVO TQD triple quadrupole mass spectrometer (Waters Corp., Milford, MA, USA) equipped with electrospray ionization (ESI) interface were used to analyze mirabegron and tolterodine. Data were processed using Masslynx 4.1 (Waters Corp., Milford, MA, USA) software. Water (containing $0.1 \%$ formic acid) was chosen as the aqueous portion of the mobile phase, and acetonitrile was selected as the organic phase in our study. Separation was achieved in $2.5 \mathrm{~min}$ by gradient elution using a UPLC ${ }^{\circledR}$ BEH C18 column $(2.1 \mathrm{~mm} \times 50$ $\mathrm{mm}, 1.7 \mu \mathrm{m})$. The column was kept at $40^{\circ} \mathrm{C}$ with a flow rate of $0.35 \mathrm{~mL} / \mathrm{min}$. The injection volume was of $2 \mu \mathrm{L}$. Elution was in a linear gradient. In the progress of elution, acetonitrile content was changed from 45 to $95 \%$ between 0.3 and $1.3 \mathrm{~min}$. Organic phase acetonitrile was maintained at $95 \%$ for $1 \mathrm{~min}$. Then in the next 0.2 $\mathrm{min}$, it was decreased to $45 \%$. The positive ionization mode was used for compound ionization with nitrogen (flow rate of $800 \mathrm{~L} / \mathrm{h}$, cone gas of $50 \mathrm{~L} / \mathrm{h}$ ) as the desolvation gas. Argon was used as the collision gas. Table 1 showed the main working parameters of the mass spectrometer. The MRM transitions were $\mathrm{m} / \mathrm{z}$ $397.3 \rightarrow 379.6$ and $\mathrm{m} / \mathrm{z} \quad 326.4 \rightarrow 121.0$ for Mirabegron and IS, respectively (Fig.1).

Standard solutions, quality control (QC) sample, and calibration standards

A total of $10 \mathrm{mg}$ Mirabegron and tolterodine were dissolved respectively in methanol to obtain a concentration of $2.00 \mathrm{mg} / \mathrm{mL}$ and $1.0 \mathrm{mg} / \mathrm{mL}$ standard stock solution. The stock solutions of the standards were further diluted in methanol to produce combined standard working solutions at a series of concentrations. The concentrations of Mirabegron QC samples in rat plasma were $25,500,2000 \mathrm{ng} / \mathrm{mL}$. The IS working solution was diluted from the 1.00 $\mathrm{mg} / \mathrm{mL}$ tolterodine stock solution to make the final concentration at $250 \mathrm{ng} / \mathrm{mL}$. The lower limit of quantitation (LLOQ) was defined as the lowest concentration on the calibration curves. The LOD was defined as a signal/noise ratio $>3$. The concentration levels of plasma calibration standards were 5, 10, 50, 100, 250, 500, 1000, and $2500 \mathrm{ng} / \mathrm{mL}$. They were prepared by spiking $10 \mu \mathrm{L}$ working standard solutions into $90 \mu \mathrm{L}$ blank plasma (vortexed for $30 \mathrm{~s}$ ). All stock solutions were kept at $-40^{\circ} \mathrm{C}$ until to use. 
TABLE 1. MASS-TO-CHARGE (M/Z) VALUES FOR PROTONATED MIRABEGRON AND TOLTERODINE OBTAINED BY ESI+ AND MASS TRANSITIONS USED FOR QUANTIFICATION IN THE MRM MODE.

\begin{tabular}{l|l|l|l|l|l}
\multirow{2}{*}{ Drug } & {$[\mathrm{M}+\mathrm{H}]+$} & Mass transition & Capillary & Cone voltage & Collision \\
\cline { 2 - 6 } & $(\mathrm{m} / \mathrm{z})$ & $(\mathrm{m} / \mathrm{z}$ to $\mathrm{m} / \mathrm{z})$ & $(\mathrm{KV})$ & $(\mathrm{V})$ & energy \\
\hline Mirabegron & 397.34 & $397.34 \rightarrow 379.67$ & 0.7 & 35 & 15 \\
\hline Tolterodine & 326.47 & $326.47 \rightarrow 121.07$ & 1 & 50 & 30 \\
\hline
\end{tabular}

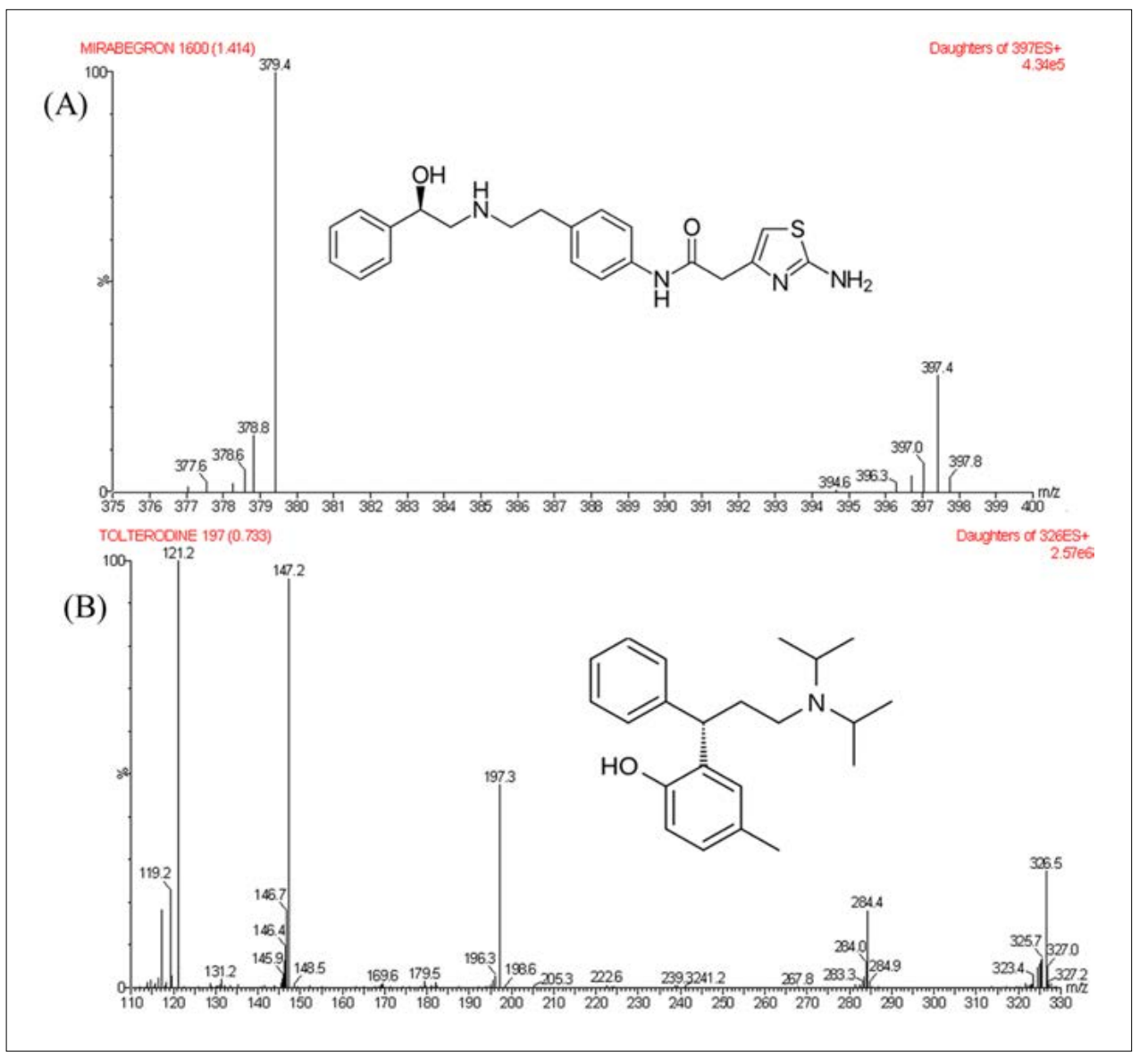

FIGURE 1. The mass spectrum and chemical structures of Mirabegron and IS in the present study: (A) Mirabegron; (B) Tolterodine (IS).

\section{Sample preparation}

Deproteinization using acetonitrile was applied as a reliable and straightforward technique for sample preparation. All frozen plasma samples were thawed and vortex-mixed before analysis. Plasma $100 \mu \mathrm{L}$ followed by $30 \mu \mathrm{L}$ IS $(50 \mathrm{ng} / \mathrm{mL}$ ) and $200 \mu \mathrm{L}$ acetonitrile were added into fresh $1.5 \mathrm{~mL}$ clean EP tubes. The tubes were vortexed thoroughly for $2.0 \mathrm{~min}$ to mix well and then spun in a centrifuge at $13000 \mathrm{rpm}$ for $10 \mathrm{~min}$. The upper organic phase $100 \mu \mathrm{L}$ was carefully transferred into $0.5 \mathrm{~mL}$ clean glass tubes and was diluted with an equal volume of water. Then 2 $\mu \mathrm{L}$ supernatant was put for analysis by UPLC-MS/ MS system after vortex mixed.

\section{Method validation}

According to the Guidance for Industry, Bioan- alytical Method Validation of the Food and Drug Administration (USFDA) ${ }^{12}$ and European Medical Agency (EMA) guidelines ${ }^{13}$ of bioanalytical method validation, selectivity, linearity, precision, accuracy, recovery, stability and matrix effect were the items of validation.

Mixed blank plasma from ten rats was used for the evaluation of the selectivity of the method towards endogenous plasma matrix. The chromatograms of a blank sample, a blank plasma sample spiked with Mirabegron and IS, and a rat plasma sample 15 min after oral administration of a single dosage of 20.0 $\mathrm{mg} / \mathrm{kg}$ Mirabegron are shown in Fig.2.

To evaluate the linearity, concentrations with seven points of Mirabegron were generated using the analyte to IS peak area ratios by weighted $\left(1 / \mathrm{x}^{2}\right)$ least squares linear regression on three consecutive days. 
The precision and accuracy of the method were assessed by determining QC samples in rat plasma at different concentrations $(25,500,2000 \mathrm{ng} / \mathrm{mL}$ for Mirabegron in rat plasma) on three separate days. Precision was expressed by the intra- and inter-day relative standard deviation (RSD), required to be less than $15 \%$. Accuracy was expressed as the relative error ( $\mathrm{RE}=$ measured value/true value-1) with an acceptance criterion of $\pm 15 \%$ for all QC samples.

Peak area ratios of Mirabegron from plasma samples spiked with a known concentration of unextracted samples and the extraction of the blank plasma at the same concentration at three QC levels $(25 \mathrm{ng} / \mathrm{mL}$, $500 \mathrm{ng} / \mathrm{mL}, 2000 \mathrm{ng} / \mathrm{mL}$ ) were used as the percent extraction recoveries.

Stability was examined in all matrices at 3 QC concentrations $(n=5)$ under different conditions: at room temperature for $12 \mathrm{~h}$, in the autosampler at room temperature for $12 \mathrm{~h}$, on storage at $-40^{\circ} \mathrm{C}$ for 30 days, and through three complete freeze-thaw cycles. All of the stability testing QC samples were determined by using the calibration curve of freshly prepared standard samples.

The matrix effect (ME) was evaluated by comparing the ratio ( $\left.\mathrm{A} / \mathrm{B}{ }^{*} 100 \%\right)$ of peak response of Mirabegron containing an equivalent amount both extracting from blank plasma (A) and dissolved in pure standard solution (B).

\section{Application to a pharmacokinetic study}

The pharmacokinetic study was carried out in ten healthy male Sprague-Dawley rats $(250 \pm 20 \mathrm{~g})$ obtained from the Laboratory Animal Center of Wenzhou Medical University (Wenzhou, China). All ani-

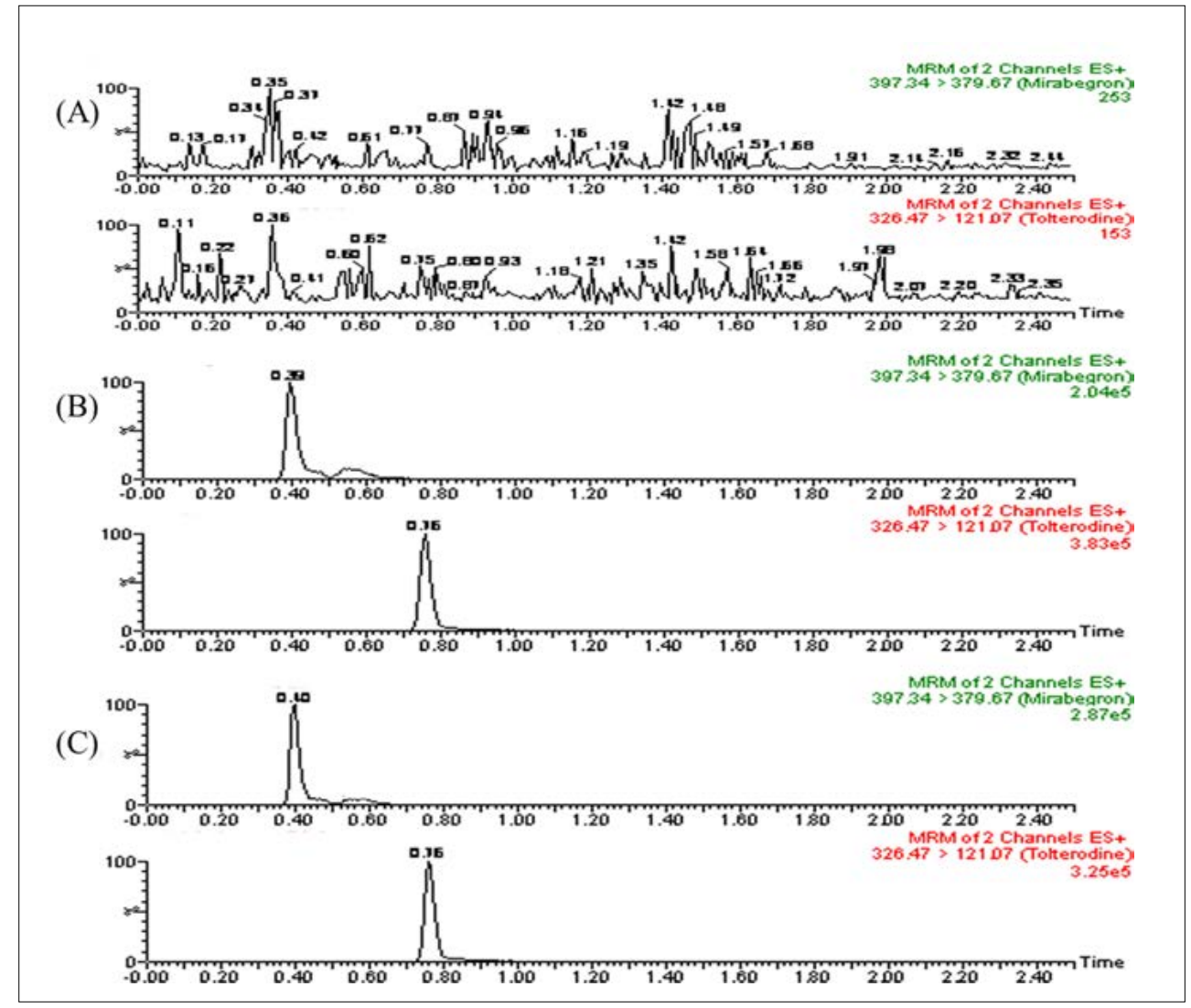

FIGURE 2.

Representative chromatograms of Mirabegron and IS in rat plasma samples. (A) a blank plasma sample; (B) a blank plasma sample spiked with $50 \mathrm{ng} / \mathrm{ml}$ Mirabegron and IS; (C) a rat plasma sample $15 \mathrm{~min}$ after oral administration of a single dosage of 20.0 $\mathrm{mg} / \mathrm{kg}$ Mirabegron.

TABLE 2. PRECISION, ACCURACY, AND RECOVERY FOR MIRABEGRON OF THE QUALITY CONTROL SAMPLE IN RAT PLASMA $(N=6)$.

\begin{tabular}{l|l|l|l|l|l|l}
\multirow{2}{*}{ Analyte } & $\begin{array}{l}\text { Concentra- } \\
\text { tion }(\mathrm{ng} / \mathrm{mL})\end{array}$ & Found $(\mathrm{ng} / \mathrm{mL})$ & \multicolumn{2}{l|}{ CV(\%) } & Accuracy RE $(\%)$ & Recovery(\%) \\
\cline { 3 - 7 } Mirabegron & 25 & $23.8573 \pm 2.75$ & 11.06 & 11.43 & -4.61 & 84.95 \\
\cline { 2 - 6 } & 500 & $495.50 \pm 14.71$ & 2.98 & 3.83 & -0.90 & 92.81 \\
\cline { 2 - 6 } & 2000 & $2001.82 \pm 12.54$ & 0.97 & 0.81 & 0.09 & 93.26 \\
\hline
\end{tabular}


mals were housed in an environmentally controlled room which was maintained at a temperature of 20 $\pm 5^{\circ} \mathrm{C}$ and a relative humidity of $50-60 \%$, with natural light-dark cycles. The rats were allowed to adapt to these conditions for at least one week. All experimental procedures and protocols were reviewed and approved by the Animal Care and Use Committee of Wenzhou Medical University and followed the Guide for the Care and Use of Laboratory Animals. All rats were randomly divided into two groups $(n=5$ per group): Group A (oral administration of mirabegron at $20 \mathrm{mg} / \mathrm{kg}$ ), Group B (intravenous administration of mirabegron at $10 \mathrm{mg} / \mathrm{kg}$ ). Rats fasted for at least $12 \mathrm{~h}$ before mirabegron administration, but water was freely available. The blood samples $(0.5 \mathrm{ml})$ were collected into heparinized tubes from the tail vein at $0,0.083,0.167,0.333,0.5,1,2,3,4,6,8,12$ and $24 \mathrm{~h}$ after oral or intravenous administration of mirabegron (dissolved in normal saline, homogenized at $36^{\circ} \mathrm{C}$ for $\left.30 \mathrm{~min}\right)$. The samples collected were then centrifuged at $13000 \mathrm{rpm}$ for $10 \mathrm{~min}$ immediately. Plasma samples separated from whole blood were transferred into $0.5 \mathrm{~mL}$ clean centrifuge tubes as soon as possible and stored at $-40{ }^{\circ} \mathrm{C}$ until analysis. The pharmacokinetic parameters were evaluated by non-compartmental modeling using DAS version 3.0 (Bontz Inc., Beijing, China).

\section{RESULTS AND DISCUSSION}

\section{Method development and optimization}

Different columns, such as UPLC ${ }^{\circledR}$ BEH C18 (2.1 $\mathrm{mm} \times 50 \mathrm{~mm}, 1.7 \mu \mathrm{m})$, UPLC BEH C18 Column(2.1 $\mathrm{mm} \times 100 \mathrm{~mm}, 1.7 \mu \mathrm{m})$, UPLC $^{\circledR}$ BEH HILIC $(2.1 \mathrm{~mm}$ $\times 50 \mathrm{~mm}, 1.7 \mu \mathrm{m})$ were compared for chromatographic separation. The UPLC ${ }^{\circledR}$ BEH C18 $(2.1 \mathrm{~mm} \times$ $50 \mathrm{~mm}, 1.7 \mu \mathrm{m}$ ) column demonstrated satisfactory chromatographic results with minimal matrix effects and proper retention time for mirabegron and tolterodine over other columns. The mobile phase played a critical role in achieving good chromatographic behavior and appropriate ionization ${ }^{14,15}$. To produce the best response, sensitivity, separation efficiency, and appropriate ionization, several mobile phase systems were tested to identify the optimal mobile phase. The mobile phase systems of acetonitrile-water and methanol-water at various ratios were tested, and different buffers including formic acid, acetic acid, and ammonium acetate were evaluated. Finally, a mobile phase of acetoni- trile and formic acid (0.1\%) in water was selected as the best solvent mixture. Various compounds (oxybutynin, tolterodine, solifenacin, midazolam) were tested to decide on a suitable IS which gave satisfactory validation results of UPLC quantification. Finally, we select tolterodine as IS for its proper retention time and favorable peak shape at the optional condition. Multiple reaction monitoring (MRM) mode was used as MS method for quantification of mirabegron and IS, and the electrospray ionization (ESI) source was operated in both positive and negative modes for ion detection. The ion source parameters were optimized to get a proper response. Solid-phase extraction and Liquid-liquid extraction are effective means to improve the sensitivity and robustness of assays ${ }^{16,17}$. However, both of them are time-consuming and expensive and may result in environmental pollution. In our work, we offered sample preparation with a simple protein precipitation method of plasma protein by acetonitrile, which can reduce the sample preparation time when compared with that of solid-phase extraction or liquid-liquid extraction. The whole separation of the analyte and IS was completed within only $2.5 \mathrm{~min}$ per sample, which was much quicker than that of previously proposed methods. Mirabegron and IS were eluted at about 0.39 and $0.76 \mathrm{~min}$, respectively.

\section{Calibration curve and sensitivity}

The standard calibration curves for mirabegron in rat plasma exhibited excellent linearity over the concentration range $5-2500 \mathrm{ng} / \mathrm{mL}\left(\mathrm{r}^{2}>0.999\right)$ using weighted least square linear regression analysis with a weight factor of $1 / \mathrm{x}^{2}$. A typical equation of the calibration curve is: $\mathrm{y}=0.000220848 \mathrm{x}+0.00239281$, $\mathrm{r}=0.999942, \mathrm{r}^{2}=0.999884$, where $\mathrm{y}$ represents the ratios of mirabegron peak area to that of IS and $x$ represents the plasma concentration. Fig.2 showed the representative chromatograms of mirabegron and IS in the rat plasma sample. No endogenous interference at the retention time of analytes and the IS was observed. The LLOQ and LOD for determining mirabegron in plasma was $5 \mathrm{ng} / \mathrm{mL}$ and $1 \mathrm{ng} / \mathrm{mL}$, respectively.

Precision, accuracy, recovery, and matrix effect

Assay performance data were presented in Table 2. Intra-day precision was $11.06 \%$ or less, and the inter-day precision was $11.43 \%$ or less at three levels 
of mirabegron. The accuracy of the method ranged from -4.61 to 0.09 at each QC level. The mean recoveries of mirabegron extracted from plasma were $84.95 \%, 92.81 \%, 93.26 \%$ at concentrations of 25,500 and $2000 \mathrm{ng} / \mathrm{mL}$ (Table 2), respectively. The results demonstrated that the values were within the acceptable range and the method was accurate and precise. The matrix effects determined at concentrations of low, medium, high for mirabegron were 89.32\% (RSD \%, 9.16), $90.23 \%$ (RSD \%, 4.11), and $95.41 \%$ (RSD \%, 1.60), respectively. The matrix effect for IS (250 ng/ $\mathrm{ml})$ was $91.2 \%$ with the RSD of $4.55 \%(\mathrm{n}=6)$. As a re-

TABLE 3. SUMMARY OF STABILITY OF MIRABEGRON UNDER VARIOUS STORAGE CONDITIONS ( $\mathrm{N}=5)$.

\begin{tabular}{l|l|l|l|l}
\multirow{2}{*}{ Condition } & \multicolumn{2}{|l|}{ Concentration(ng/mL) } & CV(\%) & $\begin{array}{l}\text { Accura- } \\
\text { cy(RE\%) }\end{array}$ \\
\cline { 2 - 5 } & $\begin{array}{l}\text { Nomi- } \\
\text { nal }\end{array}$ & Found & & \\
\hline \multirow{2}{*}{ Ambient,12h } & 25 & $23.12 \pm 2.76$ & 11.97 & -7.51 \\
\cline { 2 - 5 } & 500 & $512.05 \pm 17.13$ & 3.34 & 2.41 \\
\cline { 2 - 5 } & 2000 & $2017.22 \pm 22.72$ & 1.13 & 0.86 \\
\hline Autosample, & 25 & $23.01 \pm 2.33$ & 10.11 & -7.95 \\
\cline { 2 - 5 } ambient, 12h & 500 & $509.67 \pm 19.40$ & 3.81 & 1.93 \\
\cline { 2 - 5 } & 2000 & $2017.48 \pm 15.10$ & 0.75 & 0.87 \\
\hline Three freeze-thaw & 25 & $22.35 \pm 2.87$ & 12.86 & -10.59 \\
\cline { 2 - 5 } & 500 & $505.74 \pm 18.39$ & 3.64 & 1.15 \\
\cline { 2 - 5 } & 2000 & $2005.19 \pm 16.07$ & 0.80 & 0.26 \\
\hline \multirow{2}{*}{$-40{ }^{\circ}$ C, 50 days } & 25 & $22.94 \pm 3.14$ & 13.71 & -8.26 \\
\cline { 2 - 5 } & 500 & $505.14 \pm 24.29$ & 4.81 & 1.03 \\
\cline { 2 - 4 } & 2000 & $1988.28 \pm 17.01$ & 0.86 & -0.59 \\
\hline
\end{tabular}

TABLE 4. THE MAIN PHARMACOKINETIC PARAMETERS AFTER ORAL ADMINISTRATION OF 2O.0 MG/KG MIRABEGRON AND INTRAVENOUS ADMINISTRATION OF 10.0 MG/KG MIRABEGRON IN THE PLASMA OF TEN RATSPLASMA

\begin{tabular}{l|l|l} 
Parameters & $\begin{array}{l}\text { Mirabegron } \\
\text { (oral) }\end{array}$ & $\begin{array}{l}\text { Mirabegron (intrave- } \\
\text { nous) }\end{array}$ \\
\hline $\mathrm{t}_{1 / 2}(\mathrm{~h})$ & $3.207 \pm 0.415$ & $4.471 \pm 0.571$ \\
\hline $\mathrm{T}_{\max }$ & $3.000 \pm 0.000$ & $0.083 \pm 0.000$ \\
\hline $\mathrm{C}_{\max }(\mathrm{ng} / \mathrm{mL})$ & $829.06 \pm 38.245$ & $9643.37 \pm 3812.36$ \\
\hline$A \cup C_{0 \rightarrow \mathrm{t}}(\mathrm{ng} / \mathrm{mL} h)$ & $4214.66 \pm 1068.33$ & $13776.37 \pm 4409.77$ \\
\hline$A \cup C_{0 \rightarrow \infty}(\mathrm{ng} / \mathrm{mL} h)$ & $4243.65 \pm 1081.86$ & $13990.66 \pm 4465.37$ \\
\hline$M R T_{0 \rightarrow t}(\mathrm{~h})$ & $5.234 \pm 0.341$ & $3.961 \pm 0.789$ \\
\hline$M R T_{0 \rightarrow \infty}(h)$ & $5.389 \pm 0.376$ & $4.378 \pm 0.882$ \\
\hline $\mathrm{CLz} / \mathrm{F}(\mathrm{L} / \mathrm{h} / \mathrm{kg})$ & $4.99 \pm 1.367$ & $0.774 \pm 0.237$ \\
\hline
\end{tabular}

sult, the matrix effect from plasma was negligible in this method. These results indicated that the method was reproducible.

\section{STABILITY}

All stability studies of mirabegron in rat plasma were conducted at three concentration levels (25, 500 and $2000 \mathrm{ng} / \mathrm{mL}$ ). The results of stability tests of mirabegron in rat plasma are summarized in Table 3 and are well within the acceptable limit. Mirabegron was demonstrated to be stable after being placed at room temperature for $12 \mathrm{~h}$, in the autosampler at room temperature for $12 \mathrm{~h}$, stored at $-40{ }^{\circ} \mathrm{C}$ for 30 days, and after three complete freeze-thaw cycles. Moreover, the established method was suitable for the pharmacokinetic study.

\section{Application of the method in a pharmacoki-} netic study

The pharmacokinetic study dosing of mirabegron (dissolved in normal saline) via oral and intravenous administration was performed successfully to validate UPLC-MS/MS method. The plasma concentration-time curves of mirabegron are shown in Fig.3. A non-compartmental model was applied to calculate the following pharmacokinetic parameters: t1/2, Tmax, Cmax, AUC, CL. All parameters were summarized in Table 4 . It was found that oral administration of mirabegron had a much lower Cmax $(829.06 \pm 38.245 \mathrm{ng} / \mathrm{mL})$, AUCO-t (4214.66 $\pm 1068.33 \mathrm{ng} / \mathrm{mL}$ h) , AUCO $\rightarrow \infty(4243.65 \pm 1081.86$ $\mathrm{ng} / \mathrm{mL} \mathrm{h})$ than that of intravenous administration $(9643.37 \pm 3812.36 \mathrm{ng} / \mathrm{mL}, 13776.37 \pm 4409.77 \mathrm{ng} /$ $\mathrm{mL} h$ and $13990.66 \pm 4465.37)$ in rat plasma. According to the formula to calculate $\mathrm{F}(\%)=\mathrm{AUC}$ oral $/ \mathrm{AUC}$ intravenous $\times 100 \%$. The $\mathrm{F}$ Value of Oral administration absolute bioavailability is $15.17 \%$. The Tmax, the clearance $\mathrm{CL} / \mathrm{F}$ of oral mirabegron was 36 -folds and 6.45-folds than that of intravenous administration, respectively.

\section{CONCLUSION}

A rapid, sensitive and accurate UPLC-MS/MS method for quantifying mirabegron in rats was established for the first time and validated for linearity, accuracy, precision, recovery, and stability.

The validation has proved this method is reproducible, sensitive, and robust. To the best of 
(A)

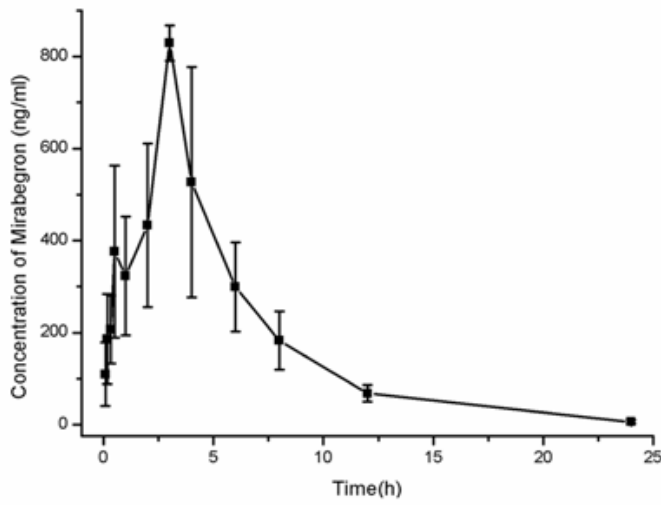

(B)

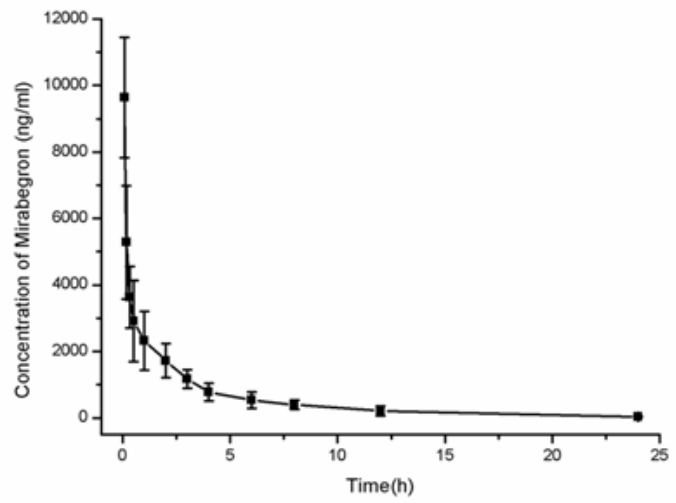

(A)

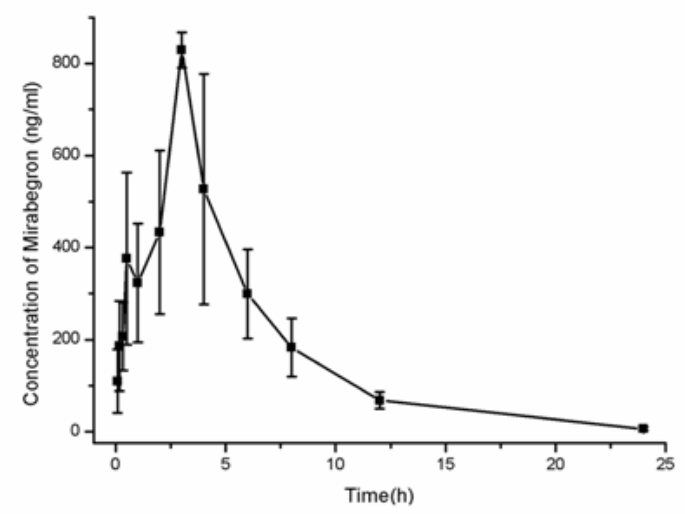

(B)

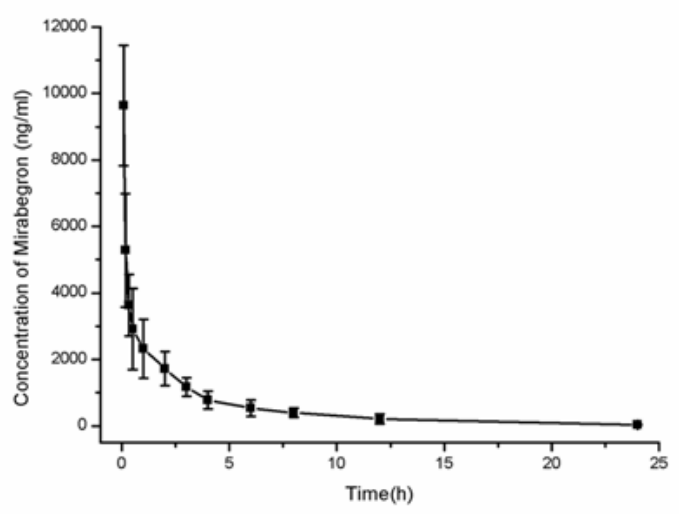

FIGURE 3. Mean plasma concentration time profile after oral administration of $20.0 \mathrm{mg} / \mathrm{kg}$ Mirabegron and intravenous administration of $10.0 \mathrm{mg} / \mathrm{kg}$ Mirabegron in ten rats.

our knowledge, this is the first report of determining the mirabegron level in rat plasma using a UPLC-MS/MS method. The LLOQ of $5 \mathrm{ng} / \mathrm{mL}$ for mirabegron in plasma was achieved, and a simple protein precipitation procedure was developed with average extraction recoveries over $84.95 \%$ for each analyte. Compared to other studies, one of the main advantages offered by the method developed is the shorter running time which meets the requirement of high throughput in bioanalysis. To sum up, the validated method has been successfully applied to the pharmacokinetic study of mirabegron in rats, and we suggest it could be applied to human pharmacokinetic studies in the near future.

\section{Conflict of Interest}

There is no conflict of interest.

\section{Acknowledgments}

This work was supported by the Ministry of Health of the People's Republic of China (201302008).

\section{RESUMO}

Mirabegron é um tipo de agonista do receptor adrenérgico beta 3 que demonstra eficácia no tratamento de bexiga hiperativa. Nesta pesquisa, o método UPLC-MS/MS é desenvolvido e validado para o estudo da farmacocinética mirabegron em ratos. Um método de precipitação de proteínas é aplicado para a preparação de amostras com acetonitrilo. $397.3 \rightarrow 379.6$ M / Z, M / Z $326.4 \rightarrow 121.0$ para mirabegron, tolterodina (IS), respectivamente, para o íon positivo foi realizado para quantificação. O método éfiável e reprodutivel em nosso estudo (precisão intradia $\leq 11,06 \%$; precisão entredia $\leq 11.43 \%$ ), com curvas de concentração linear de 5 a $2 \mathrm{ng} / \mathrm{ml}(R 2>0,999)$. Estudos de estabilidade demonstraram que mirabegron permanece estável sob uma variedade de condições de armazenamento. Este método foi aplicado com sucesso para a determinação de mirabegron em ratos após administração oral e intravenosa.

PALAVRAS-CHAVE: Bexiga urinária hiperativa. Agonistas de receptores adrenérgicos beta 3. Plasma. Administração intravenosa. Administração oral. Ratos. 


\section{REFERENCES}

1. Bragg R, Hebel D, Vouri SM, Pitlick JM. Mirabegron: a beta-3 agonist for overactive bladder. Consult Pharm. 2014;29(12):823-37.

2. Milsom I, Stewart W, Thüroff]. The prevalence of overactive bladder. Am J Manag Care. 2000;6(11 Suppl):S565-73.

3. Wallace KM, Drake MJ. Overactive bladder. F1000Res. 2015;4.

4. Irwin DE, Kopp ZS, Agatep B, Milsom I, Abrams P. Worldwide prevalence estimates of lower urinary tract symptoms, overactive bladder, urinary incontinence, and bladder outlet obstruction. BJU Int. 2011;108(7):1132-8.

5. Maman K, Aballea S, Nazir J, Desroziers K, Neine ME, Siddiqui E, et al. Comparative efficacy and safety of medical treatments for the management of overactive bladder: a systematic literature review and mixed treatment comparison. Eur Urol. 2014;65(4):755-65.

6. Robinson D, Thiagamoorthy $G$, Cardozo L. A drug safety evaluation of mirabegron in the management of overactive bladder. Expert Opin Drug Saf. 2016;15(5):689-96

7. litsuka H, Tokuno T, Amada Y, Matsushima H, Katashima M, Sawamoto T, et al. Pharmacokinetics of mirabegron, a $\beta 3$-adrenoceptor agonist for the treatment of overactive bladder, in healthy Japanese male subjects: results from single- and multiple-dose studies. Clin Drug Investig. 2014;34(1):2735.

8. Takusagawa S, Yajima K, Miyashita A, Uehara S, Iwatsubo T, Usui T. Identification of human cytochrome P450 isoforms and esterases involved in the metabolism of mirabegron, a potent and selective $\beta 3$-adrenoceptor agonist. Xenobiotica. 2012;42(10):957-67.

9. Sawamoto T, Lee J, Alak A, Meijer J, Roy M, Zha J, et al. Phase I, open-label, drug interaction study to evaluate the effect of multiple doses of ketoconazole on single dose mirabegron (YM178) oral controlled absorption system (OCAS) in healthy adult subjects. Clin Pharmacol Therap. 2011; 89: S21.
10. Teijlingen R, Meijer J, Takusagawa S, Gelderen M, Beld C, Usui T. Development and validation of LC-MS/MS methods for the determination of mirabegron and its metabolites in human plasma and their application to a clinical pharmacokinetic study. J Chromatogr B Analyt Technol Biomed Life Sci. 2012;887-888:102-11.

11. Zhou F, Zhou Y, Zou Q, Sun L, Wei P. Liquid chromatographic separation and thermodynamic investigation of mirabegron enantiomers on a chiralpak AY-H column. J Chromatogr Sci. 2015;53(8):1361-5.

12. US Food and Drug Administration. Bioanalytical method validation: guid ance for industry. [cited 2018 Jan 22]. Available from: https://www.fda. gov/downloads/drugs/guidances/ucm070107.Pdf

13. European Medicines Agency. Guideline on bioanalytical method validation. 2012. [cited 2018 Jan 22]. Available from: https://www.ema.europa. eu/documents/scientific-guideline/guideline-bioanalytical-method-validation_en.pdf

14. Wang $X$, Chen $M$, Wen $C$, Zhang Q, Ma I. Determination of chidamide in rat plasma by LC-MS and its application to pharmacokinetics study. Biomed Chromatogr. 2013;27(12):1801-6.

15. Zhang Q, Wen C, Xiang Z, Ma J, Wang X. Determination of CUDC101 in rat plasma by liquid chromatography mass spectrometry and its application to a pharmacokinetic study. I Pharm Biomed Anal. 2014;90:134-8

16. Ni KH, Wen ZD, Huang XC, Wang CX, Ye TT, Hu GX, et al. Determination of trifolirhizin in rat plasma by UPLC: application to a pharmacokinetic study. I Chromatogr B Analyt Technol Biomed Life Sci. 2015:990:181-4.

17. Wang J, Cheng C, Yang Y. Determination of estrogens in milk samples by magnetic-solid-phase extraction technique coupled with high-performance liquid chromatography. | Food Sci. 2015;80(12): C2655-61. 